\title{
Environmental impacts of European trade: interpreting results of process-based LCA and environmentally extended input-output analysis towards hotspot identification
}

\author{
Antoine Beylot ${ }^{1} \cdot$ Sara $_{\text {Corrado }}{ }^{1} \cdot$ Serenella Sala $^{1}$ (D) \\ Received: 4 January 2019 / Accepted: 5 June 2019 / Published online: 1 July 2019 \\ (C) The Author(s) 2019
}

\begin{abstract}
Purpose Trade is increasingly considered a significant contributor to environmental impacts. The assessment of the impacts of trade is usually performed via environmentally extended input-output analysis (EEIOA). However, process-based life cycle assessment (LCA) applied to traded goods allows increasing the granularity of the analysis and may be essential to unveil specific impacts due to traded products.

Methods This study assesses the environmental impacts of the European trade, considering two modelling approaches: respectively EEIOA, using EXIOBASE 3 as supporting database, and process-based LCA. The interpretation of the results is pivotal to improve the robustness of the assessment and the identification of hotspots. The hotspot identification focuses on temporal trends and on the contribution of products and substances to the overall impacts. The inventories of elementary flows associated with EU trade, for the period 2000-2010, have been characterized considering 14 impact categories according to the Environmental Footprint (EF2017) Life Cycle Impact Assessment method.

Results and discussion The two modelling approaches converge in highlighting that in the period 2000-2010: (i) EU was a net importer of environmental impacts; (ii) impacts of EU trade and EU trade balance (impacts of imports minus impacts of exports) were increasing over time, regarding most impact categories under study; and (iii) similar manufactured products were the main contributors to the impacts of exports from EU, regarding most impact categories. However, some results are discrepant: (i) larger impacts are obtained from IO analysis than from process-based LCA, regarding most impact categories, (ii) a different set of most contributing products is identified by the two approaches in the case of imports, and (iii) large differences in the contributions of substances are observed regarding resource use, toxicity, and ecotoxicity indicators.

Conclusions The interpretation step is crucial to unveil the main hotspots, encompassing a comparison of the differences between the two methodologies, the assumptions, the data coverage and sources, the completeness of inventory as basis for impact assessment. The main driver for the observed divergences is identified to be the differences in the impact intensities of goods, both induced by inherent properties of the IO and life cycle inventory databases and by some of this study's modelling choices. The combination of IO analysis and process-based LCA in a hybrid framework, as performed in other studies but generally not at the macro-scale of the full trade of a country or region, appears a potential important perspective to refine such an assessment in the future.
\end{abstract}

Keywords Environmental impacts · EXIOBASE $3 \cdot$ Input-output analysis $\cdot$ LCA $\cdot$ LCA interpretation $\cdot$ Trade

Responsible editor: Alexis Laurent

Electronic supplementary material The online version of this article (https://doi.org/10.1007/s11367-019-01649-z) contains supplementary material, which is available to authorized users.

Serenella Sala

serenella.sala@ec.europa.eu

1 European Commission, Joint Research Centre, Via Enrico Fermi 2749, 21027 Ispra, VA, Italy

\section{Introduction}

The production and consumption of goods and services is responsible for global resource use and associated environmental impacts. As a response, the international community advocates fundamental changes in the way societies produce and consume for achieving global sustainable development (UN 2012), defining a specific sustainable development goal (SDG) addressing responsible consumption (SDG12; UN 2015). These commitments on "The future we want" are taken 
in a context of continuous increase of consumption expenditures in the world. From 1961 to 2017, world final consumption expenditures of households and non-profit institutions serving households have continuously increased (except in 2009), with annual growth rates ranging from 1.3 to $6.1 \%$ (World Bank 2018).

In this context, the pressures exerted on the environment, and ultimately on the impacts these pressures induce, have been studied both in a producer and in a consumer perspective. According to the producer perspective, any sector/ country emitting a substance or extracting a resource is considered responsible for this emission/extraction (often called domestic or territorial emission/extraction), whereas from the consumer perspective, the final consumer is considered responsible for the supply chain emissions and resource extractions. Such a shift in the perspective on the assessment of environmental impacts has opened the door to a growing attention to the burdens associated with trade. In the scientific literature, a number of studies have aimed at assessing how much global pressures are displaced through trade, in particular demonstrating that most developed countries have increased their consumption-based carbon dioxide $\left(\mathrm{CO}_{2}\right)$ emissions faster than their territorial emissions (Peters et al. 2011). Similarly, the influence of international trade has been studied not only considering greenhouse gas emissions but also material use (Wiedmann et al. 2015), land use (Weinzettel et al. 2013), nitrogen oxides $\left(\mathrm{NO}_{x}\right)$, sulfur dioxide $\left(\mathrm{SO}_{2}\right)$ and ozone depleting substances (Kanemoto et al. 2014), eutrophication (Hamilton et al. 2018), biodiversity (Lenzen et al. 2012), or a set of these indicators (Steen-Olsen et al. 2012; Wood et al. 2018).

All these studies have been conducted by implementing environmentally extended input-output analysis (EEIOA). Moreover, some other studies tackling the environmental impacts of consumption have been performed by combining EEIOA and process-based life cycle assessment (LCA) in a hybrid framework. Huppes et al. (2006) quantified the environmental impacts of consumption in the European Union (EU), while other studies focused on smaller geographical scales. Heinonen and Junnila (2011), for example, quantified the impacts of two metropolitan cities in Finland, Pairotti et al. (2015) quantified energy consumption and greenhouse gas emissions of the Mediterranean diet, and Guan et al. (2016) assessed the energy embodied in buildings in China.

Only recently, process-based LCA has been used to study the environmental impacts associated with trade, in the specific case of the EU (Corrado et al. 2019). The pros and cons of EEIOA and process-based LCA are well known and acknowledged by the scientific community (see, e.g., Rebitzer et al. 2002). On the one hand, process-based LCA has the advantage of enabling a more flexible modelling, at a larger level of disaggregation. Indeed, it gives the possibility to analyze the impacts of single life cycle stages and products, and it generally covers a higher number of emissions and resources. Besides, process-based LCA allow more flexibility in running scenarios product-specific, includig those related to consumers behaviour. On the other hand, EEIOA enables to capture a complete picture of economic exchanges, not only considering goods but also services, and allocates environmental interventions along the supply chain in a world multiregional framework (yet generally considering a lower scope of environmental interventions compared to process-based LCA).

The global trade in goods and services has increased by 47\% (in economic value) from 2007 to 2017, the EU representing $16.7 \%$ of these total exchanges in 2017 (EC 2018). In this context, this study aims at assessing the environmental impacts of EU trade, with a specific focus on trends and on the contribution of products and specific emissions and resource used. Two modelling approaches are considered: on the one hand, EEIOA, using EXIOBASE 3 as the supporting database and, on the other hand, process-based LCA. The key research question is as follows: how far these two modelling approaches, different in terms of coverage of products, services and environmental interventions, of data sources, of level of disaggregation, etc., lead to common messages to support policy decisions on the potential outsourcing of European environmental impacts through trade? Compared to the existing literature relative to the environmental impact assessment at a macro-scale (e.g., focusing on trade), this study brings two key novelties. Firstly, the common characterization framework used for both modelling approaches enables to go beyond the mere pressure-based indicators, or limited set of characterized impact indicators, as usually considered in such studies. Moreover, two approaches (respectively, EEIOA and process-based LCA) are implemented and put in perspective, whereas existing studies consider one modelling approach only (in most cases, EEIOA), stressing the relevance of the LCA results interpretation step. In fact, the implementation and comparison of these two modelling approaches enables the identification of converging, and therefore robust, conclusions for policy-makers. In the meantime, it enables to underline the drivers for the discrepancies in the results, and it therefore paves the way towards improvements in the use of each modelling approach in future similar studies.

\section{Methods}

Input-output analysis, referred to as IO analysis in the following, is implemented together with impact assessment methods to assess the environmental impacts of EU trade in the period of time 2000-2010 (Sects. 2.1 and 2.3; Fig. 1). These impact assessment results, including contribution analyses, are put in perspective with those obtained from the process-based LCA study recently performed by Corrado et al. (2019), whose 


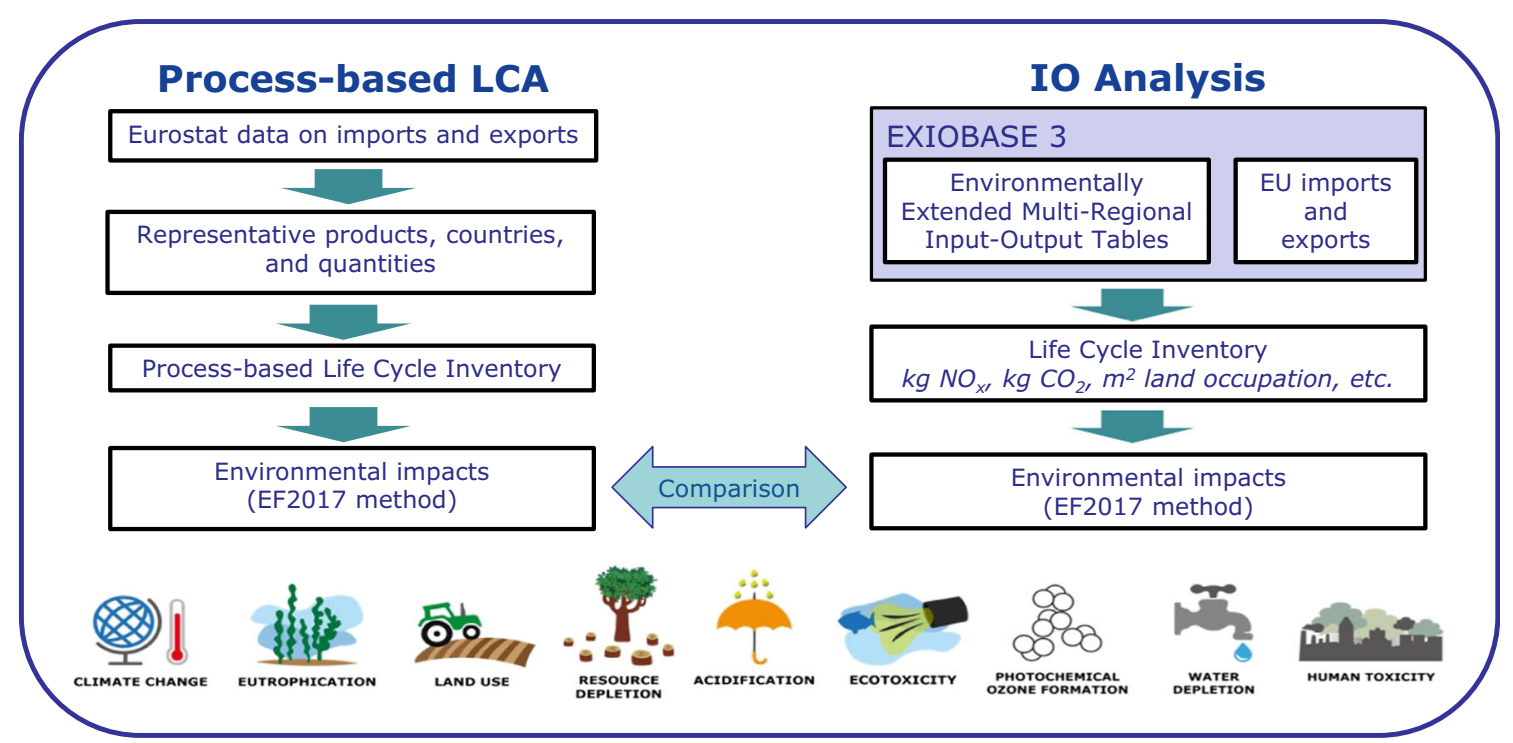

Fig. 1 Quantifying the environmental impacts of EU trade with IO analysis and process-based LCA: scheme of the modelling approaches implemented

approach is recalled in Sect. 2.2. Total EU trade, considering the EU, is the basis for the comparison in this study: IO analysis could be additionally used for an analysis at the scale of EU countries, but so far, this has not been done in the processbased LCA approach. The two modelling approaches are used to build two life cycle inventories (LCIs, respectively, processbased and IO analysis-based) which are characterized using the Environmental Footprint (EF2017; EC 2017) as the common life cycle impact assessment (LCIA) method.

\subsection{Life cycle inventory compiled by use of multi-regional input-output analysis}

The standard Leontief inverse equation (Leontief 1970) is implemented to quantify the environmental pressures induced by EU trade:

$x=(I-A)^{-1} f$

$g=B x=B(I-A)^{-1} f$

considering $x$ the vector of output productions, $A$ the technological requirement matrix, $f$ the final demand (including exports), $B$ the matrix of resources and emission intensities per economic activity, and $g$ the vector of environmental interventions (that is, the LCI) induced by the final demand. Multiregional input-output (MRIO) models extend the standard IO models by distinguishing each industry in each country/region through separate rows and columns (Hertwich and Peters 2010). In this study, the hybrid version of the MRIO database EXIOBASE is implemented to perform calculations (namely EXIOBASE 3.3.8, referred to as EXIOBASE 3 in the following; Stadler et al. 2018; Merciai and Schmidt 2018; Table 1). Imports to and exports from the EU Member States are drawn from EXIOBASE 3 considering years 2000 to 2011
( $f$ in Eqs. (1) and (2)). Results for years 2000 to 2010 are used to analyze the trends in impacts in a time-frame common to that of process-based LCA, while results for 2011 are specifically considered to perform contribution analyses (expected to be the most up-to-date and reliable year among the EXIOBASE data series for any analysis at a disaggregated level). In the hybrid version of EXIOBASE 3, 164 categories of products and services are differentiated, either in physical units (regarding most goods) or monetary units (primarily regarding services). Trade is mapped considering 43 countries, including the EU Member States at stake in this study, plus 5 rest-of-world regions. The IO tables used for calculations integrate investments based on the approach developed in the project FORWAST (Schmidt 2010), so that IO analysis accounts for "capital goods" similarly to process-based LCA.

\subsection{Life cycle inventory compiled by use of process-based LCA}

The process-based LCA study performed by Corrado et al. (2019) with respect to the EU trade of goods is considered as a point of comparison (Table 1). Results are available with respect to four years: 2000, 2005, 2010, and 2014. However, for sake of comparison with IO analysis, only the period 2000-2010 is considered in this study. Whereas results from IO analysis are available for the full period 2000-2010, results from process-based LCA are linearly interpolated for the years between 2000 and 2005, and between 2005 and 2010 .

The approach undertaken by Corrado et al. (2019) primarily consists in three steps (for more details, readers are referred to the corresponding article and in Sala et al. 2019):

- The selection of representative products and, in case of imports, of representative countries of origin, based on 
Table1 Main characteristics of two modelling approaches adopted in this study

\begin{tabular}{|c|c|c|}
\hline & IO analysis & Process-based LCA \\
\hline $\begin{array}{l}\text { Main data sources supporting the LCI } \\
\text { calculations }\end{array}$ & Hybrid version of EXIOBASE 3.3 .8 & ecoinvent 2.2 combined with Eurostat data on trade \\
\hline Granularity of products and services & 164 categories & 20 product groups respectively for imports and exports \\
\hline Nomenclature used & $\begin{array}{l}\text { EXIOBASE, i.e., NACE (Statistical classification of } \\
\text { economic activities in the European } \\
\text { Community) + some more disaggregated categories }\end{array}$ & $\begin{array}{l}\text { HS2: Harmonized Commodity Description and Coding } \\
\text { System with two digits }\end{array}$ \\
\hline Comprehensiveness of exchanges & Whole trade & Whole trade of goods \\
\hline Trading partners (for imports) & 20 countries and regions & $\begin{array}{l}3 \text { representative countries for each imported product } \\
\text { group, upscaled to represent the full imports }\end{array}$ \\
\hline Years covered & From 2000 to 2011 & $2000,2005,2010$ (and 2014) \\
\hline Number of elementary flows & 78 & More than 1500 \\
\hline Impact assessment method & EF2017 method (14 impact categories) & $\begin{array}{l}\text { EF2017 method (16 impact categories, } 14 \text { applied here } \\
\text { to compare with IO) }\end{array}$ \\
\hline
\end{tabular}

data reported in the COMEXT database (Eurostat 2018). For both imports and exports, 20 product groups were selected: 15 by criteria of mass and five by criteria of value. For each of those 20 product groups, reported according to the Harmonized Commodity Description and Coding System with two digits (HS2) nomenclature, a representative product was selected at a finer level of disaggregation (considering the Combined Nomenclature with 8 digits; CN8). Finally, regarding imports to EU, the three countries with the largest mass exported to EU (by product group) were selected as the representative ones.

- The modelling of LCI relative to each representative product considering standard databases (PE and ecoinvent 2.2), complemented when necessary with data from LCA reports, other technical literature, and expert judgment. Despite the availability of more recent versions of the ecoinvent database, the version 2.2 was chosen as it enables to model life cycles of products essentially considering the period 2000-2005. This is consistent with the temporal coverage considered in this study (2000-2010), for which the EXIOBASE 3 tables are available and implemented. The production of imported products was modelled using as far as possible country-specific data. When country-specific data were not available, data from countries with similar production patterns were considered. The transport of imported products from producing countries was modelled considering statistical data on the shares of transport means, complemented by expert judgment when necessary (Corrado et al. 2019). The LCI datasets were set to be constant in the modelling, therefore not accounting for changes in technologies in the period under study whereas these changes were partly accounted for through IO analysis (only "partly," considering that the construction of the hybrid version of EXIOBASE 3 also includes the use of some fixed coefficients, e.g., fixed emission factors; Merciai and Schmidt
2018). Co-products are handled differently in each modelling approach, respectively by allocation in process-based LCA (using PE and ecoinvent 2.2 as the main supporting databases) and by using the by-producttechnology model in EXIOBASE (which is equivalent to system expansion; Suh et al. 2010).

- And finally, three upscaling, aimed to cover the overall impacts of imports and exports of EU. Firstly, from the three representative countries to all the countries of origin; secondly, from the representative product to the whole set of products in the product group; and thirdly, from the selected product groups to the total imports and exports (see also Electronic Supplementary Material, Document 1).

\subsection{Environmental impact assessment}

The inventories of elementary flows associated with EU trade, as obtained from each modelling approach, are characterized considering 14 impact categories according to the EF2017 LCIA method (EC 2017): climate change; acidification; terrestrial eutrophication; marine eutrophication; freshwater eutrophication; particulate matter; photochemical ozone formation; human toxicity, cancer effects; human toxicity, noncancer effects; freshwater ecotoxicity; land use; water use; minerals and metals resource use; and fossils resource use. In addition, ozone depletion and ionizing radiation were considered in Corrado et al. (2019) but excluded from the present study because ionizing radiations are missing in EXIOBASE 3 environmental extensions, while ozonedepleting substances are in most cases not reported neither. Despite the EF2017 LCIA method reports spatially resolved characterization factors for some impact categories (acidification, terrestrial eutrophication, land use, and water use), only global average characterization factors are used in this study, 
due to limited availability of spatially differentiated life cycle inventories.

On the one hand, the inventory calculated from IO analysis distinguishes 78 elementary flows in total, including 36 mineral, metal, and energy resources; 5 types of land occupation; 3 types of water consumption; and 29 substances emitted to air, 2 to water and 3 to soil. The correspondence between the EXIOBASE and the EF2017 nomenclatures of elementary flows, built by Beylot et al. (2019) for application to the analysis of impacts of EU final consumption, is implemented in this study. On the other hand, the inventory obtained from the process-based LCA approach is much more detailed, including more than 1500 elementary flows both for imports and exports.

\section{Results and discussion}

The total environmental impacts induced by EU trade are firstly compared considering the period 2000-2010 (Sects. 3.1 and 3.2), discussing the common patterns and on the contrary the discrepancies in results from the two modelling approaches. Then, Sects. 3.3, 3.4, and 3.5 aim at analyzing the contributions of products and services, and substances, both discussing the main convergences in contributions and the major drivers for the differences in EU trade balance and trends of impacts (as described in the previous sections). It is to be noted that one potential major driver (namely, results uncertainty) is not considered in this study. Whereas uncertainty analysis tends to become common practice in processbased LCA (e.g., by use of the pedigree matrix when implementing ecoinvent as the supporting LCI database; Weidema and Wesnaes 1996), no such framework currently exists to perform uncertainty calculations with EXIOBASE 3.

\subsection{Environmental impacts of trade: the EU trade balance}

Overall, considering the assessed 14 impact categories and the period 2000-2010, the two modelling approaches converge in estimating higher impacts of imports than of exports (Fig. 2 and Table 2). Said in other words, both approaches converge in demonstrating that EU is a net importer of environmental impacts. Regarding results from IO analysis, such conclusion is drawn considering the whole 14 impact categories and almost all years under study (the only exception being fossils resource use in the years 2000 to 2003; Fig. 2). When instead considering process-based LCA, a larger number of exceptions (still, limited) depart from the observed global trend: human toxicity, cancer (regarding all years under study: 2000, 2005 and 2010) and non-cancer (years 2000 and 2010), freshwater eutrophication (2000 and 2010), minerals and metals resource use (2000 and 2010), and land use (2010). These exceptions are mainly associated with products with high value added and long supply chains, which are generally mainly exported from EU rather than imported (Corrado et al. 2019). In the process-based LCA approach, the impact on minerals and metals resource use, for example, is mainly associated with copper used for the production of Machineries both for imports and for exports. Regarding years 2000 and 2010, the mass of Machineries imported was lower than the one exported, largely explaining the predominance of the impact of exports on that of imports regarding minerals and metals resource use.

IO analysis shows that, on average over the period 2000 2010, impacts from imports are 43 to $77 \%$ larger than those from exports regarding the 14 impact categories except fossils resource use (Fig. 2 and Electronic Supplementary Material, Document 1). Similarly, considering process-based LCA and years 2000, 2005, and 2010, environmental impacts from imports are observed to be 39 to $80 \%$ larger than those from exports regarding most impact categories (namely acidification, climate change, freshwater ecotoxicity, marine and terrestrial eutrophication, photochemical ozone formation, fossils resource use, and particulate matter). Yet, according to the process-based LCA approach, impacts associated with imports are 15 to $96 \%$ lower than those of exports regarding human toxicity (cancer and non-cancer) and minerals and metals resource use, whereas IO analysis identifies larger impacts of imports for these three impact categories (from 43 to $47 \%$ larger over the period 2000-2010; Electronic Supplementary Material, Document 1). Furthermore, as a complementary remark, it has to be noted that regarding land use and water use the absence of spatially resolved characterization factors in this study is expected to influence the discrepancy between impacts of imports and exports, to an extent that is not scrutinized further here.

When comparing impacts of trade according to each modelling approach, one observes that IO analysis results in larger values than process-based LCA considering almost all the impact categories and years under study (Fig. 2 and Table 2). The only exceptions (that is, processbased values larger than IO-based values) are observed regarding freshwater ecotoxicity (both considering exports and imports in the three years under study; 2000, 2005, and 2010), freshwater eutrophication (exports only, in years 2005 and 2010), human toxicity cancer (years 2000, 2005, and 2010; mainly regarding exports) and non-cancer (imports and exports in 2000; Fig. 2 and Table 2). The larger impacts calculated from the processbased LCA approach compared to IO analysis with respect to human toxicity, cancer, and freshwater ecotoxicity, are primarily due to the larger scope of toxic emissions accounted for (this aspect is further detailed in Sect. 3.4 relative to the contribution of substances). Regarding the year 2010, results from IO analysis are larger than those from process-based LCA, by a factor 2 


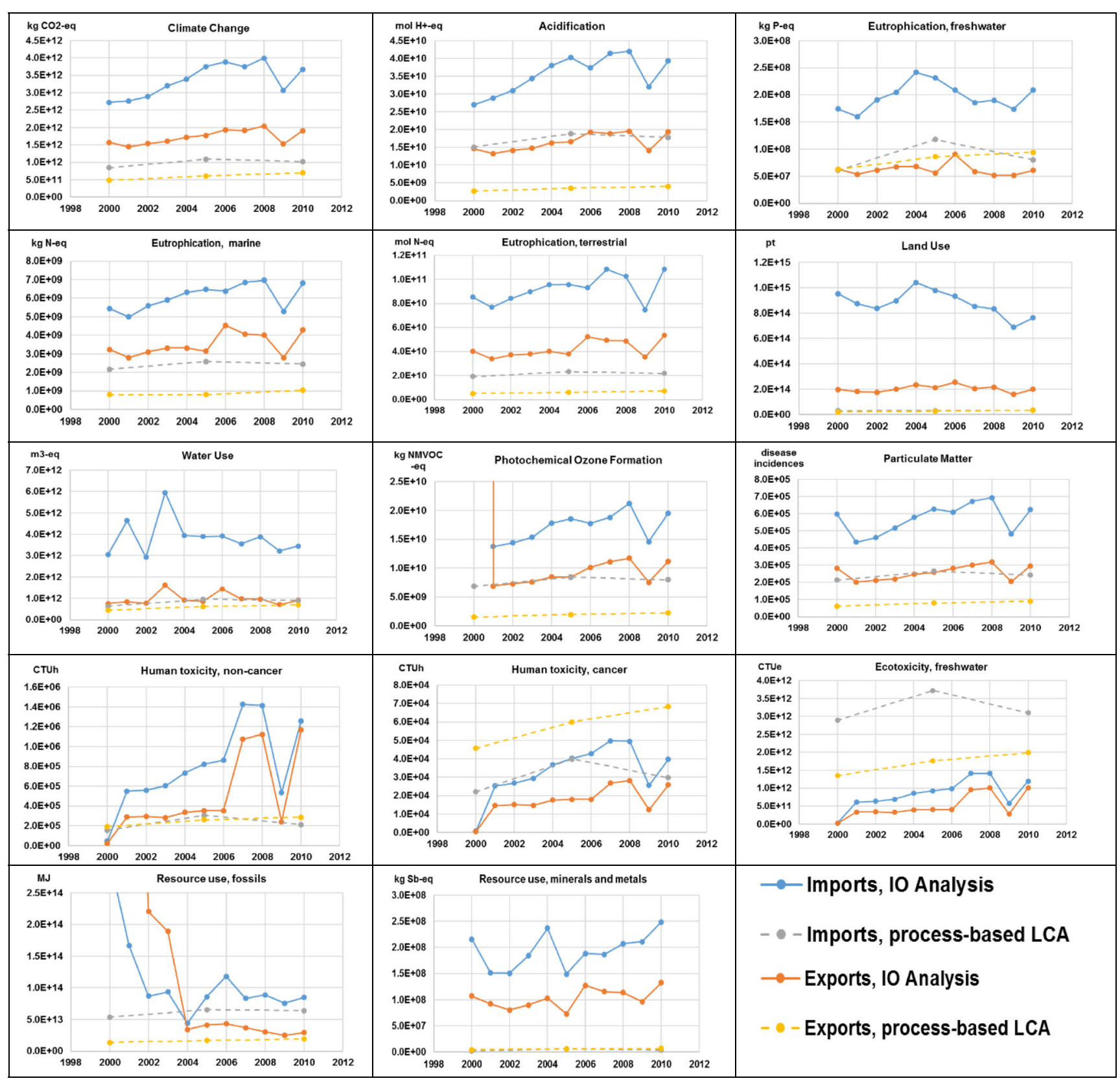

Fig. 2 Environmental impacts of EU trade considering IO analysis (referring to years from 2000 to 2010) and process-based LCA (years 2000, 2005, and 2010), distinguishing 14 impact categories

for most impact categories (Table 2), that is a discrepancy larger than that usually observed between existing MRIO databases when considering the consumption-based accounts of pressures (e.g., Moran and Wood 2014; Giljum et al. 2019). The discrepancy is particularly large regarding terrestrial eutrophication and human toxicity, non-cancer (up to a factor 7.5 of difference) and land use and minerals and metals resource use (factor of difference ranging from 6 to 66 depending on the impact category and the nature of the trade componentimports or exports; Table 2).

\subsection{Trends of impacts of trade from 2000 to 2010}

Both modelling approaches globally show an increase in impacts from EU imports and exports in 2010 compared to 2000. This is the case regarding all impact categories under study according to process-based LCA, and most impact categories according to IO analysis; that is, all impact categories except fossils resource use (imports and exports), freshwater eutrophication (exports), and land use (imports; Fig. 2 and Electronic Supplementary Material, Document 1). Considering IO analysis, it is noteworthy that the variations 
Table 2 Environmental impacts of EU trade in 2010, calculated from IO analysis (EXIOBASE 3) and process-based LCA (Corrado et al. 2019)

\begin{tabular}{|c|c|c|c|c|c|c|c|c|c|}
\hline & & \multicolumn{2}{|c|}{$\begin{array}{l}\text { Total trade (goods) } \\
\text { Process-based LCA }\end{array}$} & \multicolumn{2}{|c|}{$\begin{array}{l}\text { Total trade (goods and } \\
\text { services) } \\
\text { IO analysis }\end{array}$} & \multicolumn{2}{|c|}{$\begin{array}{l}\text { Total trade } \\
\text { Ratio: IO analysis/ } \\
\text { process-based LCA }\end{array}$} & \multicolumn{2}{|c|}{$\begin{array}{l}\text { Goods* } \\
\text { Ratio: IO analysis } \\
\text { process-based LCA }\end{array}$} \\
\hline & & Imports & Exports & Imports & Exports & Imports & Exports & Imports & Exports \\
\hline Climate change & $\mathrm{kg} \mathrm{CO}_{2}$ eq & $1.02 \mathrm{E}+12$ & $6.96 \mathrm{E}+11$ & $3.67 \mathrm{E}+12$ & $1.91 \mathrm{E}+12$ & 3.6 & 2.7 & 3.1 & 2.1 \\
\hline Acidification & $\mathrm{mol} \mathrm{H}^{+} \mathrm{eq}$ & $1.78 \mathrm{E}+10$ & $4.02 \mathrm{E}+09$ & $3.93 \mathrm{E}+10$ & $1.93 \mathrm{E}+10$ & 2.2 & 4.8 & 1.8 & 3.5 \\
\hline Eutrophication, freshwater & $\mathrm{kg} \mathrm{P}$ eq & $8.02 \mathrm{E}+07$ & $9.43 \mathrm{E}+07$ & $2.09 \mathrm{E}+08$ & $6.09 \mathrm{E}+07$ & 2.6 & 0.6 & 1.8 & 0.5 \\
\hline Eutrophication, marine & $\mathrm{kg} \mathrm{N}$ eq & $2.45 \mathrm{E}+09$ & $1.04 \mathrm{E}+09$ & $6.82 \mathrm{E}+09$ & $4.29 \mathrm{E}+09$ & 2.8 & 4.1 & 2.0 & 3.1 \\
\hline Eutrophication, terrestrial & Mole of $\mathrm{N}$ eq & $2.18 \mathrm{E}+10$ & $7.10 \mathrm{E}+09$ & $1.09 \mathrm{E}+11$ & $5.33 \mathrm{E}+10$ & 5.0 & 7.5 & 3.4 & 5.6 \\
\hline Land use & point & $3.24 \mathrm{E}+13$ & $3.35 \mathrm{E}+13$ & $7.62 \mathrm{E}+14$ & $2.00 \mathrm{E}+14$ & 23.5 & 6.0 & 19.6 & 5.1 \\
\hline Water use & $\mathrm{m}^{3}$ world equivalent & $9.01 \mathrm{E}+11$ & $6.99 \mathrm{E}+11$ & $3.45 \mathrm{E}+12$ & $9.18 \mathrm{E}+11$ & 3.8 & 1.3 & 2.9 & 1.1 \\
\hline Photochemical ozone formation & kg NMVOC eq & 7.99E+09 & $2.27 \mathrm{E}+09$ & $1.95 \mathrm{E}+10$ & $1.12 \mathrm{E}+10$ & 2.4 & 4.9 & 2.1 & 3.6 \\
\hline Particulate matter & disease incidences & $2.42 \mathrm{E}+05$ & $9.06 \mathrm{E}+04$ & $6.23 \mathrm{E}+05$ & $2.97 \mathrm{E}+05$ & 2.6 & 3.3 & 2.2 & 2.4 \\
\hline Human toxicity, non-cancer & CTUh & $2.12 \mathrm{E}+05$ & $2.88 \mathrm{E}+05$ & $1.26 \mathrm{E}+06$ & $1.17 \mathrm{E}+06$ & 5.9 & 4.1 & 5.6 & 3.6 \\
\hline Human toxicity, cancer & CTUh & $2.98 \mathrm{E}+04$ & $6.83 \mathrm{E}+04$ & $3.97 \mathrm{E}+04$ & $2.58 \mathrm{E}+04$ & 1.3 & 0.4 & 1.3 & 0.3 \\
\hline Ecotoxicity freshwater & CTUe & $3.10 \mathrm{E}+12$ & $1.99 \mathrm{E}+12$ & $1.20 \mathrm{E}+12$ & $1.01 \mathrm{E}+12$ & 0.4 & 0.5 & 0.4 & 0.5 \\
\hline Resource use, fossils & MJ & $6.39 \mathrm{E}+13$ & $1.92 \mathrm{E}+13$ & $8.47 \mathrm{E}+13$ & $2.95 \mathrm{E}+13$ & 1.3 & 1.5 & 1.3 & 1.3 \\
\hline Resource use, minerals and metals & $\mathrm{kg} \mathrm{Sb}$ eq & $3.76 \mathrm{E}+06$ & $6.48 \mathrm{E}+06$ & $2.48 \mathrm{E}+08$ & $1.32 \mathrm{E}+08$ & 66.0 & 20.4 & 59.0 & 17.0 \\
\hline
\end{tabular}

*Goods and transport regarding imports, goods only regarding exports, estimated in the IO modelling approach considering their share for the year 2011 (Electronic Supplementary Material, Document 1). "Goods" correspond to "total trade" in the process-based LCA approach

in human toxicity cancer and non-cancer, freshwater ecotoxicity and photochemical ozone formation in the period 2000-2010 appear particularly large when put in perspective both with variations in the period 2001-2011, and with other impact categories (up to two orders of magnitude of difference; Fig. 2 and Electronic Supplementary Material, Document 1). This is expected to reflect imprecisions in the IO database supporting the calculations rather than an actual change in impact from 2000 to 2010.

Whereas both approaches underline the larger impacts of imports compared to those of exports (as discussed in Sect. 3.1 ), the process-based LCA approach highlights in the meantime that from 2000 to 2010 impacts from exports have increased at a larger pace than those from imports (regarding almost all impact categories under study; 13 out of 14 ; Electronic Supplementary Material, Document 1). While impacts of imports have increased by 7 to $57 \%$ from 2000 to 2010 , depending on the impact category, those of exports have increased by 29 to $62 \%$. On the contrary, IO analysis highlights a more balanced picture, that is higher rates of increase (or lower rates of decrease) regarding impacts of imports compared to those of exports with respect to seven impact categories out of the 14 under study, and the opposite trend (higher rates of increase regarding impacts of exports compared to those of imports) with respect to the remaining seven impact categories.

Moreover, both approaches show that the EU trade balance (impacts of imports minus impacts of exports) has increased in the meantime regarding most impact categories (10 and 11 impact categories respectively in the process-based LCA and IO analysis approaches). This is despite impacts of exports have increased at larger rates than those of imports according to the process-based LCA approach. In particular, IO analysis shows that the EU trade balance has increased from 2000 to 2010 by 3 to $25 \%$ regarding marine and terrestrial eutrophication, particulate matter, water use, and minerals and metals resource use, by 34 to $62 \%$ regarding freshwater eutrophication, climate change and acidification, and in even larger proportions regarding human toxicity (cancer and non-cancer) and freshwater ecotoxicity. The rate of increase of the EU trade balance is globally more limited according to processbased LCA, in particular ranging from 3 to $12 \%$ regarding acidification, marine and terrestrial eutrophication, photochemical ozone formation, fossils resource use and water use (yet, with a value larger than $45 \%$ regarding minerals and metals resource use, human toxicity cancer and non-cancer, and freshwater eutrophication).

\subsection{Contributions by products and services}

\subsubsection{Contributions by products and services according to IO analysis}

The 164 categories of products and services adopted to represent the trade in EU, as adopted in EXIOBASE 3, are aggregated into 9 categories in a nomenclature that enables to identify hotspot categories for the 14 environmental impact categories (Fig. 3; see Electronic Supplementary Material, Document 2 for the 

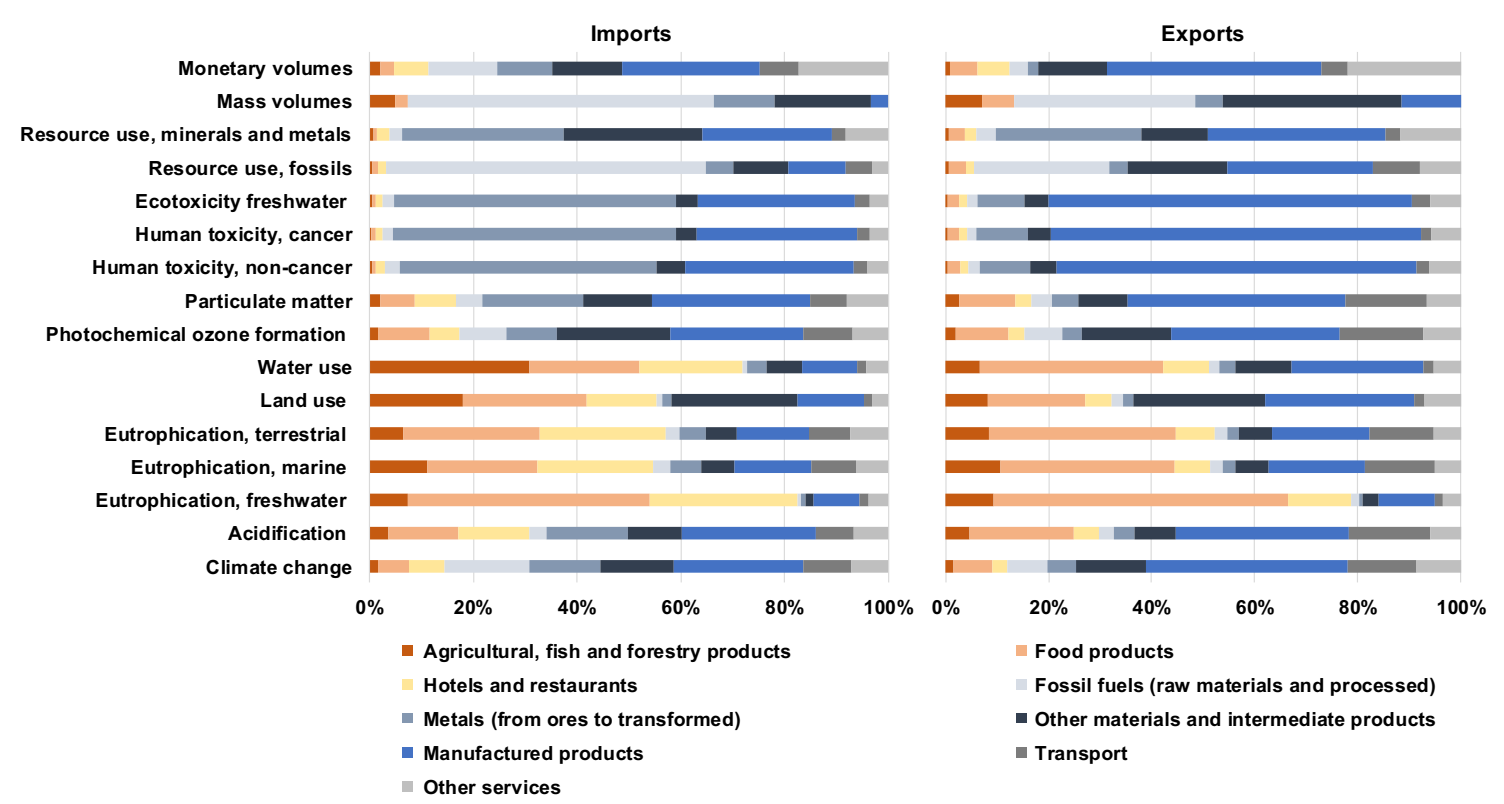

Fig. 3 Environmental impacts of EU trade calculated with IO analysis (EXIOBASE 3): contribution analysis, considering 14 impact categories and 9 categories of products and services as an aggregation of the 164 categories of products and services adopted to represent EU trade flows (year 2011)

correspondence between the nomenclature used in this figure and the EXIOBASE nomenclature of products and services).

Firstly, regarding the impacts of imports on acidification, terrestrial, freshwater and marine eutrophication, land use, and water use, food products represent an important share, ranging from $14 \%$ (in the case of acidification) to $47 \%$ (in the case of freshwater eutrophication). Among food products, meat products in particular represent a relatively important contribution with respect to eutrophication (terrestrial, marine, and freshwater) and land use (e.g., products of meat cattle stand for $12 \%, 14 \%$, and $27 \%$ of the total impacts of imports respectively on terrestrial eutrophication, land use, and freshwater eutrophication). Moreover, hotels and restaurant services represent as well a relatively large contribution (from 14 to $29 \%$ of the total impacts of imports regarding these 6 impact categories), adding to the globally large contribution of "food" to the impacts of EU imports. In addition, specifically considering water use, agricultural, fish, and forestry products stand for $31 \%$ of the total impact of imports, with the three categories of agricultural products (i) wheat, (ii) cereal grains not elsewhere classified (nec), and (iii) crops nec altogether contributing to $22 \%$. Finally, fossil fuels (raw materials and processed), metals (from ores to transformed), other materials and intermediate products (e.g., chemicals nec), and manufactured products globally show more limited contributions. Yet, these categories are still of importance regarding acidification (for which metals and manufactured products respectively contribute to 16 and $26 \%$ of the total impacts of imports) and land use (for which other materials and intermediate products, in particular wood and products of wood, represent $24 \%$ of the total impacts).
Considering the impacts of exports on the same set of impact categories, food products, and to a lower extent hotels and restaurant services, show relatively important contributions (respectively, from 19 to $57 \%$, and from 5 to $12 \%$, depending on the impact category), similarly to the case of imports. Moreover, the contribution of manufactured products (and of particular importance, of motor vehicles and of machinery and equipment nec) appears relatively important as well, in particular regarding acidification, land use, and water use for which it amounts to 26 to $33 \%$ of the total impacts. On the contrary, fossil fuels, metals, and other materials and intermediate products globally represent limited contributions (in the majority of cases, lower than $6 \%$ each), except in the specific case of land use for which other materials and intermediate products (in particular pulp and paper) stand for $25 \%$ of the total impacts of exports.

Secondly, regarding the impacts of trade on human toxicity cancer and non-cancer, and freshwater ecotoxicity, approximately half of the total impacts of imports stem from basic iron and steel. Manufactured products (motor vehicles, machinery, and equipment nec, etc.) represent the second category of most contributing products (30-32\% of the total impacts; Fig. 3). On the contrary, regarding exports, manufactured products represent from 70 to $72 \%$ of the total impacts on toxicity and ecotoxicity-related impact categories, that is much larger than any other category of products and services (e.g., the contribution of metals is lower than 10\%). Machinery and equipment nec and motor vehicles represent the main share of the impact of exported manufactured products, respectively, standing for 25-26\% and 15\% depending on the impact category. 
Moreover, regarding the impacts of imports on particulate matter, photochemical ozone formation, and climate change, the summed contributions of metals (in particular basic iron and steel) and other materials and intermediate products (in particular, rubber and plastic products) stand for 28 to $33 \%$ of the total. This contribution is similar to that of manufactured products, which overall stands for 25 to $31 \%$ of the total impacts. In addition, in the specific case of climate change, fossil fuels represent $16 \%$ of the total impact. Moreover, regarding the impacts of exports, and similarly to the case of toxicityrelated impact categories, the contribution of manufactured products (ranging from 33 to $42 \%$ of the total impacts) is even larger than their contribution to the impacts of imports. On the contrary, the cumulated contribution of metals and of other materials and intermediate products amounts to $15-21 \%$, that is lower than in the case of imports (28-33\%).

Finally, considering impacts of imports on fossils and minerals and metals resource use, materials are the largest contributors. Metals and other materials and intermediate products, respectively, represent $31 \%$ and $27 \%$ of the total impact on minerals and metals resource use, while fossil fuels represent $62 \%$ of the total impact on fossils resource use. Instead, regarding exports, manufactured products induce the major contribution in both cases of impact categories (28\% and 35\% of the total, respectively, regarding fossils and minerals and metal resource use, in particular driven by motor vehicles and machinery and equipment nec), while materials simultaneously induce a lower contribution than compared to the case of imports. In particular, metals and other materials and intermediate products respectively represent $28 \%$ and $13 \%$ of the total impact of exports on minerals and metals resource use, while fossil fuels represent $26 \%$ of the total impact on fossils resource use.

\subsubsection{Shares in exchanges and shares in impacts}

The larger contribution of manufactured products to the impacts of exports compared to their contribution to the impacts of imports is in line with their larger share in mass and monetary volumes exported compared to imported (Fig. 3). So is the lower share of fossil fuels in the impacts of exports compared to imports, in line with their lower share in the total mass and monetary volumes exported. Yet, considering the nine categories of products and services aggregated as in Fig. 3, one globally observes a limited correlation between the shares in total mass and monetary volumes traded and the shares in impacts. For example, food products and agricultural, fish and forestry products represent between 5 and $7 \%$ of the total mass and monetary volumes imported by the EU, and in the meantime $32-54 \%$ of the impacts with respect to five impact categories (freshwater, marine and terrestrial eutrophication, land use, and water use). On the contrary, whereas fossil fuels stand for $59 \%$ of the total mass imported (13\% in monetary volume), their contribution to impacts is lower than $3 \%$ regarding 10 impact categories out of the 14 under study. Similarly, in most cases of impact categories, IO analysis shows that the contribution of services (here considering the inclusion of electricity supply and hotels and restaurants services, but the exclusion of transport) to the total impacts of EU trade is lower than their share in monetary volumes, due to a lower impact intensity (in impact unit per million euros exchanged) compared to that of goods (Electronic Supplementary Material, Document 1). In particular, regarding exports, the contribution of services to the total impacts is rather limited, ranging from 7 to $16 \%$ per impact category compared to $28 \%$ in terms of total monetary volumes. Moreover, the contribution of services to the impacts of imports is also rather limited considering nine impact categories out of the 14 under study, ranging from 5 to $17 \%$ of the total impacts compared to $24 \%$ in terms of monetary exchanges (Electronic Supplementary Material, Document 1). However, regarding the remaining five impact categories (marine, freshwater and terrestrial eutrophication, acidification, and water use), the contribution of services is primarily driven by hotels and restaurant services and ranges from 20 to $32 \%$ of the total impacts of imports.

\subsubsection{Comparison with results from process-based LCA}

Overall, both the process-based LCA approach (Corrado et al. 2019; a short summary is provided in Electronic Supplementary Material, Document 1) and IO analysis show the larger contribution of manufactured products to the total impacts of exports from the EU, compared (i) to the contribution of manufactured products to the total impacts of imports and (ii) to the contribution of other exported products and services (Figs. 3 and 4). Machineries and vehicles are identified by both approaches as key contributors to impacts of exports regarding several impact categories (human toxicity, cancer and non-cancer, minerals and metals resource use, acidification, particulate matter, freshwater ecotoxicity, and to a lower extent water use and photochemical ozone formation). Yet, the larger contribution of manufactured products compared to other products is to be nuanced in the process-based LCA approach, in a context of relatively important contributions of fuels and mineral oils and iron and steel that is not observed according to IO analysis. A similar comment applies regarding results from IO analysis, specifically considering marine, freshwater and terrestrial eutrophication, and water use, for which food products and hotels and restaurant services show the major contribution to the total impacts of exports from the EU. 


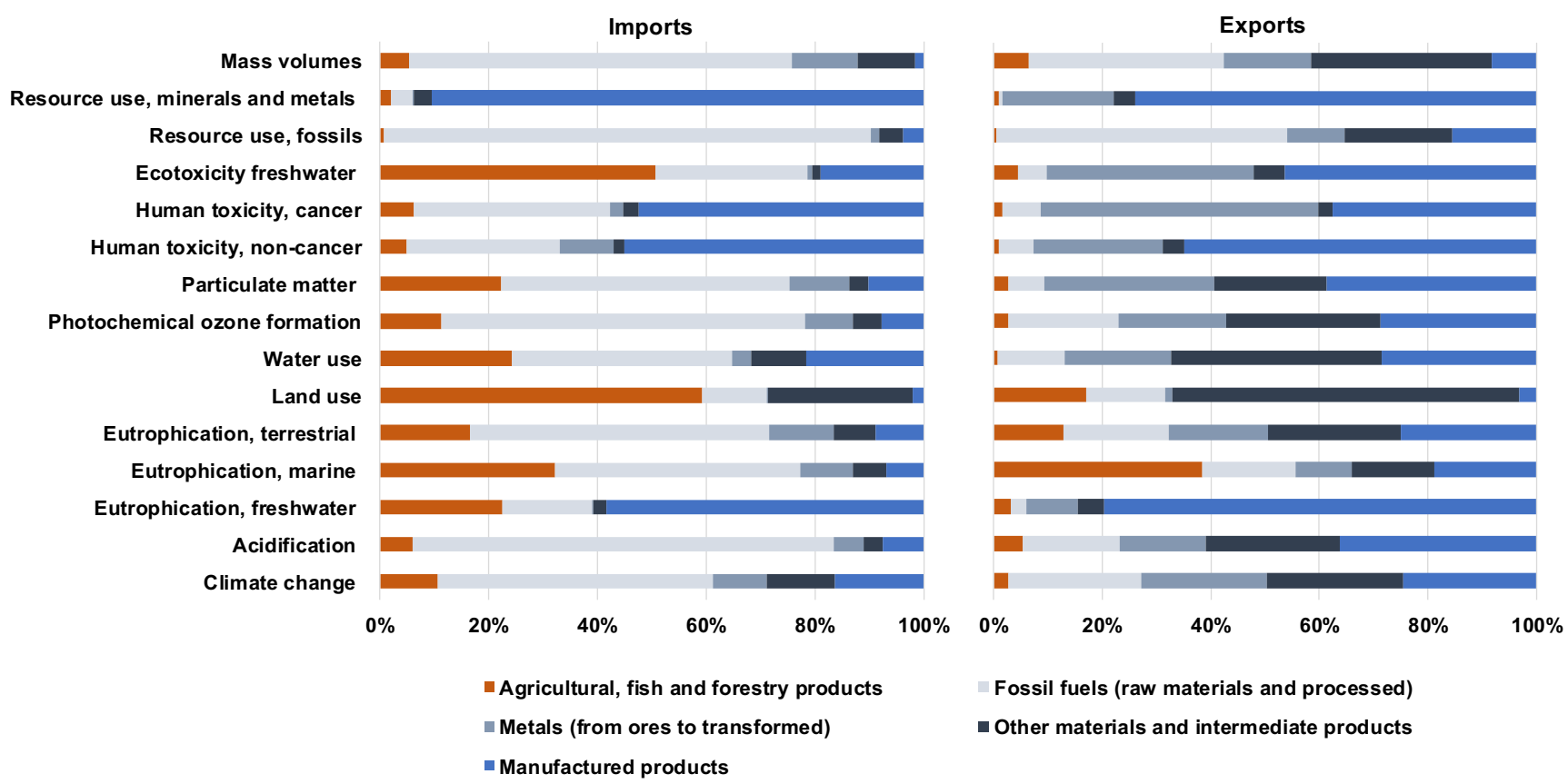

Fig. 4 Environmental impacts of EU trade calculated with process-based LCA: contribution analysis derived from Corrado et al. (2019), considering 14 impact categories and 5 categories of products as an aggregation of the 40 representative products adopted to represent EU trade flows (year 2010)

Moreover, in both modelling approaches, products with more limited supply chains are observed as the main contributors to the impacts induced by imports to EU. However, results from process-based LCA show that fuels and mineral oils are the main contributing category of products for almost all impact categories, while machineries are an important (or even the main) contributor regarding four impact categories (respectively, human toxicity cancer and non-cancer, freshwater eutrophication, and minerals and metals resource use; Fig. 4). On the contrary, IO analysis identifies fossil fuels as a key contributing category only regarding the impact on fossils resource use (and to a lower extent, on climate change), while manufactured products are observed to globally generate a lower share of the impacts of imports compared to products with more limited supply chains (still, representing from $1 / 4$ to $1 / 3$ of the total impacts of imports on climate change, acidification, photochemical ozone formation, particulate matter, human toxicity cancer and non-cancer, freshwater ecotoxicity, and minerals and metals resource use). Instead, IO analysis identifies as main contributing categories: (i) food products (in particular products of meat), hotels and restaurant services, and to a lower extent agricultural products (that is, overall, products and services related to the food system) regarding acidification, terrestrial, freshwater and marine eutrophication, land use and water use, and (ii) materials, and of most importance metals (in particular basic iron and steel) and other materials and intermediate products (in particular rubber and plastic products) regarding human toxicity cancer and non-cancer, freshwater ecotoxicity, particulate matter, photochemical ozone formation, climate change, and minerals and metal resource use.

\subsubsection{Distinct impact intensities of goods as the drivers for the differences}

Differences in the goods' impact intensity (in impact unit per unit of mass of product), and to a lower extent in the total mass of goods considered to be traded according to each modelling approach, are the two main drivers for the divergence in the total environmental impacts of trade and corresponding product contributions. The average impact intensity of goods imported and exported is in most cases larger in IO analysis than in process-based LCA, by a factor ranging from 1.1 to 2.3 with respect to eight impact categories out of 14 regarding imports (factor 1.1 to 4.6 regarding nine impact categories and exports), and even by a factor 48 regarding minerals and metals resource use (factor 14 regarding exports; Electronic Supplementary Material, Document 1). The considerable differences in the impact intensity of goods regarding minerals and metals resource use, as well as land use (Electronic Supplementary Material, Document 1), are in line with the considerable differences in terms of total impacts of imports and exports regarding these two impact categories (Table 2). They are mainly driven by differences in the scope of goods modelled (in particular, meat products as discussed in Sect. 3.3.5) and by differences in the pressure intensity of goods regarding some specific flows (especially forest land occupation, gold and other industrial minerals; see Sect. 3.4 
and Electronic Supplementary Material, Document 1, which further discuss this issue).

Moreover, a larger total mass of imported and exported goods is considered in IO analysis compared to processbased LCA (26\% and 5\% larger regarding respectively imports and exports). This larger mass of goods considered in IO analysis combines with the larger overall impact intensity per mass unit of goods, so that ultimately, for most impact categories, IO analysis results in larger environmental impacts of trade compared to the process-based LCA approach.

It is noteworthy that both approaches consider similar masses of fuels and mineral oils imported by EU (13\% of difference), but that a lower impact intensity is reported for most impact categories according to IO analysis compared to process-based LCA (Electronic Supplementary Material, Documents 1 and 2). The drivers for these differences are multiple, including the choice of a representative product in the LCA-based approach potentially departing from the full range of products included in the IO-based product category, and the different data sources for the modelling (statistical versus process-based). In the process-based LCA approach, the much larger mass of fuels and mineral oils reported to be imported compared to other goods (from 1 to 4 orders of magnitude larger as a function of the goods) drives the large share of impact of this good (Fig. 5, here considering the eight impact categories for which fuels and mineral oils are identified as the main contributors to impacts). The impact intensity of fuels and mineral oils is lower than that of many other goods in the process-based LCA approach. For example regarding acidification, the impact intensity of fuels and mineral oils (in $\mathrm{mol} \mathrm{H} \mathrm{H}^{+} \mathrm{eq} / \mathrm{kg}$ of product) is lower than that of $50 \%$ of the other goods, with a factor 6 of difference at maximum. Yet, this lower impact intensity is compensated by the much larger quantity imported compared to other goods, explaining the large contribution of fuels and mineral oils to the total impact on acidification (77\% of the total impact of goods imported; Figs. 4 and 5). Beyond acidification, now considering the seven other impact categories in Fig. 5 (terrestrial eutrophication, water use, human toxicity, cancer, climate change, photochemical ozone formation, fossils resource use, and particulate matter), a similar observation is made: fuels and mineral oils are imported in large quantities compared to other product categories and induce the largest share of the total impact of goods imported (from 36 to $89 \%$ of the total impact; Fig. 5). Instead, IO analysis identifies a larger influence of impact intensity in the calculation of the impacts of trade, ultimately resulting in a more diverse set of most contributing products. On the one hand, several goods are imported in large quantities compared to other goods but have in the meantime relatively low impact intensities, resulting in limited contributions to the total impacts of imports. For example, the mass of crude petroleum imported is at least one order of magnitude larger than the mass of $90 \%$ of the other goods imported to EU. In the meantime, here again considering acidification as an example, the impact intensity of crude petroleum is at least one order of magnitude lower than that of $79 \%$ of the other goods. Overall, this results in the minor contribution (less than 4\%) of crude petroleum to acidification, and to most of the other impacts analyzed in Fig. 5. On the other hand, several goods show a relatively large impact intensity (e.g., products of meat cattle regarding acidification and terrestrial eutrophication, crops nec. regarding water use, etc.), resulting in their relatively important contribution to the total impacts of goods, despite they are imported only in limited quantities as compared to several other products.

A thorough analysis of the temporal changes of impact intensities of products and services traded by EU, from the years 2000 to 2010 considering results from EXIOBASE 3, is out of the scope of this study. Yet, it is noteworthy that these changes in impact intensities, combined with changes in masses and monetary values traded, result in the changes in impacts of trade from 2000 to 2010. Changes of impact intensities over time reflect improvements in technology (e.g., improved energy efficiency or abatement of pollution), but also changes in the composition of goods and services traded ("within" categories of products and services, that is at a level of disaggregation finer than that considered in the EXIOBASE database), changes in trading partners, etc.

\subsubsection{Influence of services and meat products excluded from process-based LCA}

Services are accounted for in IO analysis while excluded from process-based LCA, which primarily focuses on goods (Table 1). Moreover, IO analysis accounts for the impacts of transport when quantifying the total impacts of exports, whereas the adopted process-based LCA approach does not. One may adjust impacts calculated from IO analysis considering the process-based LCA framework, that is quantifying the environmental impacts of traded goods: (i) regarding imports, by excluding the contribution of imported services to the total impacts, and (ii) regarding exports, by excluding both contributions of exported services and transport to the total impacts. Yet, doing so, IO-based impacts of EU trade are still mainly larger than those obtained from the process-based LCA approach, considering 13 impact categories in the case of imports and 10 in the case of exports, with a factor of difference larger than 2 regarding more than half of the impact categories (Table 2). Therefore, such an adjustment in the framework only partially compensates for the larger impacts in the IO approach. Said in other words, the inclusion of traded services in IO analysis only explains to a limited extent the difference in impacts observed between the two modelling approaches (Table 2 and Fig. 2).

Another potential major difference between the two modelling approaches is the absence of meat and meat-based 


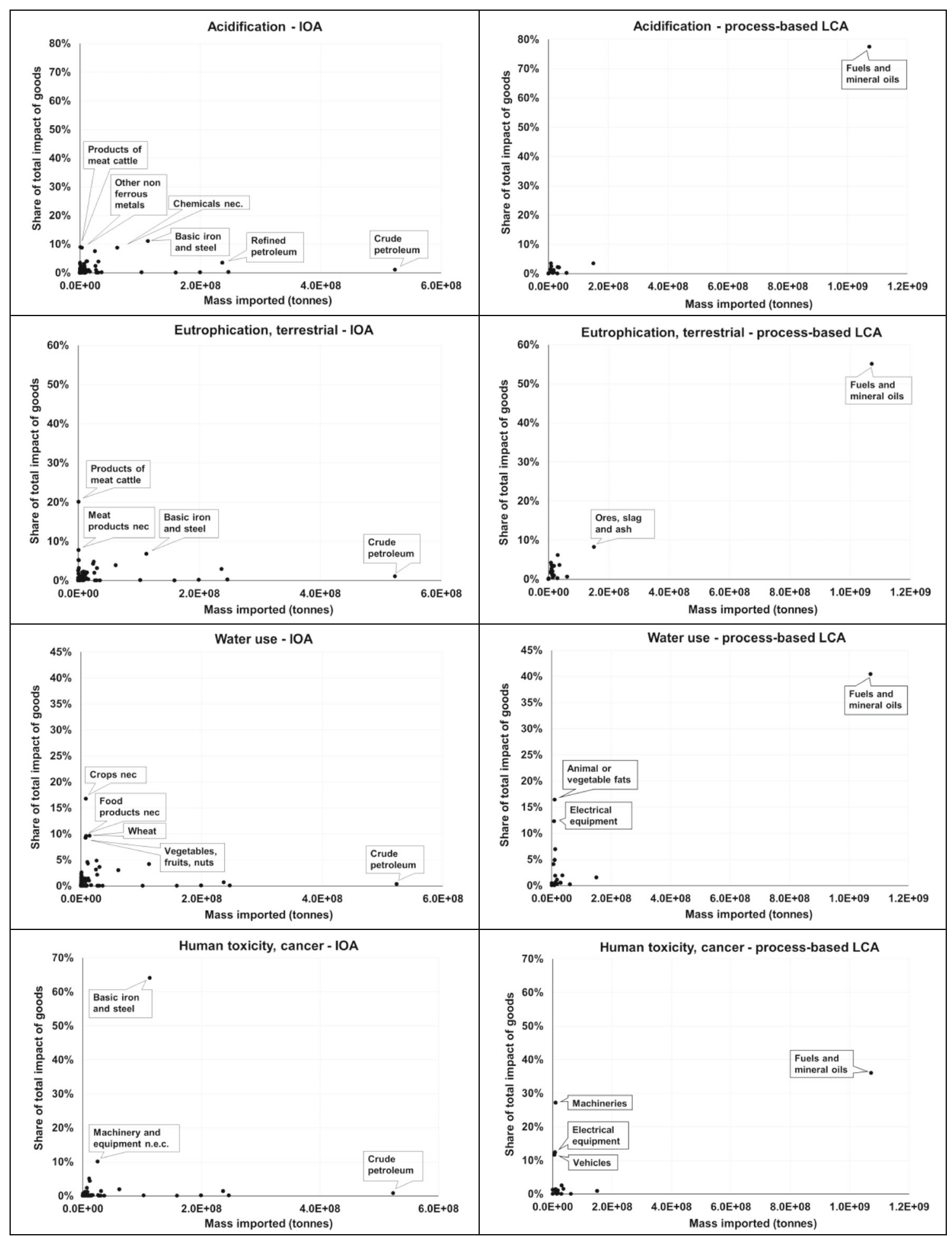

Fig. 5 Contribution of goods to the total impacts of goods imported to EU (in \%) as a function of the mass traded, distinguishing eight impact categories according to IO analysis (IOA) (year 2011) and process-based LCA (year 2010)

products in the process-based LCA. As a sensitivity analysis, the category meat and fish products is additionally accounted for in the process-based LCA modelling of imports, considering poultry and beef meats as the representative products and using the corresponding LCIs as developed by Castellani et al.
(2017) to calculate the life cycle environmental impacts of food consumption in the EU. Only a limited increase in impacts is observed: up to $4 \%$ for marine and terrestrial eutrophication and below $2 \%$ for all other impact categories. This is in contradiction with the results obtained from IO analysis 


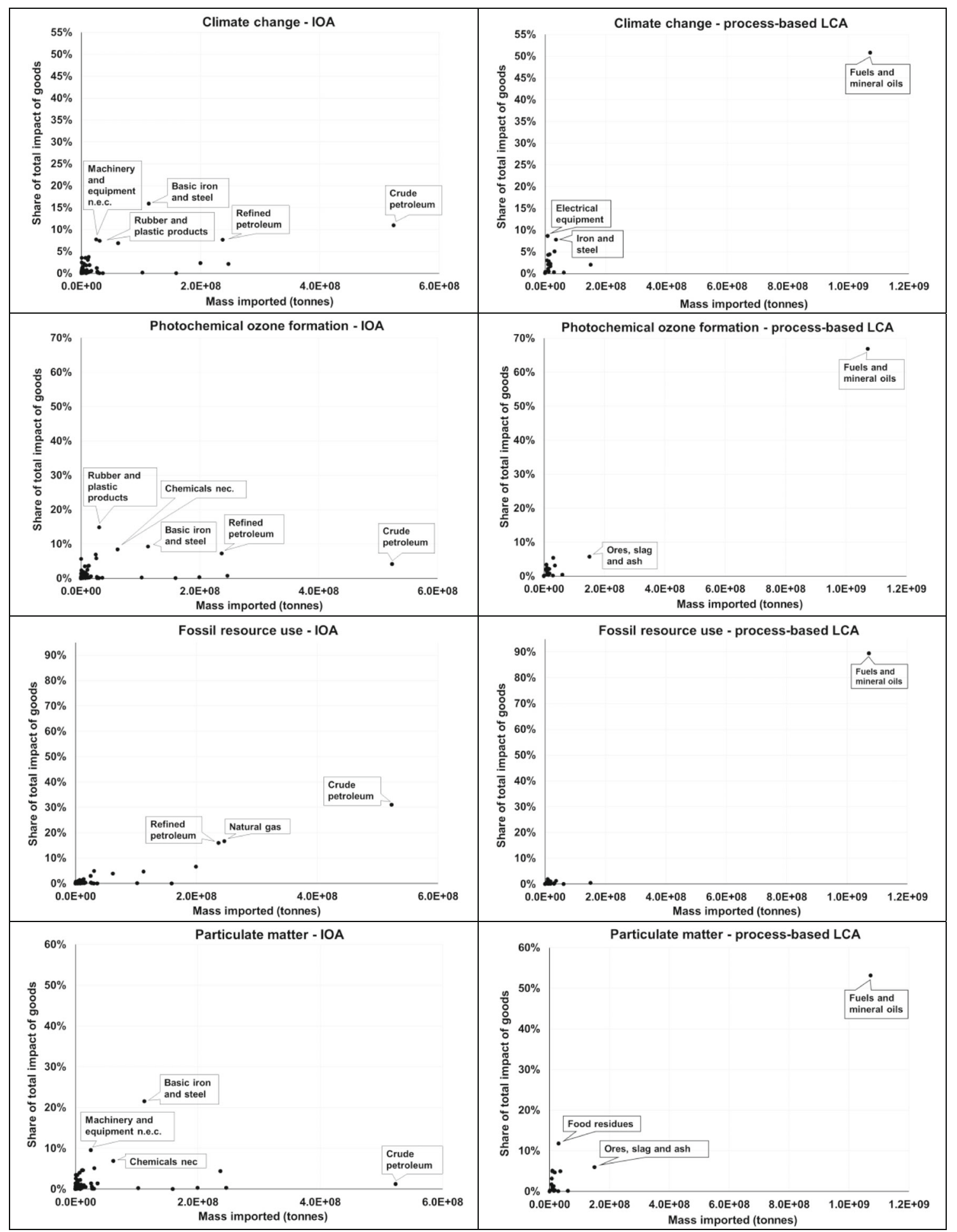

Note: IOA: Input-Output Analysis. In this figure, Motor vehicles and other transport equipments are disregarded from the results obtained from $1 O$ Analysis, as they are represented in monetary units in EXIOBASE 3

Fig. 5 continued.

which highlight that products of meat (in particular meat cattle) have an important contribution to the impacts of imports with respect to several impact categories (in particular terrestrial eutrophication, land use, and freshwater eutrophication; Fig. 3). Such difference in results is primarily driven by the very distinct impact intensities of products of meat cattle from one modelling approach to the other (in impact unit $/ \mathrm{kg}$ of products of meat cattle), whereas the distinct 
masses considered to be imported have a much lower influence. These differences in impact intensities are in particular associated with very distinct supply-chain emissions and resource consumption for some key substances and resources, due to different data sources and calculation procedures. For example, the life cycle emissions of ammonia $\left(\mathrm{NH}_{3}\right)$ per $\mathrm{kg}$ of products of meat cattle imported are more than 4 times larger in the IO analysis approach (based on EXIOBASE 3 database) than those in the process-based LCA approach (mainly using the Agrifootprint database; Castellani et al. 2017). It can be assumed (but should be further explored) that one major driver for such difference is the procedure implemented in each approach to quantify manure (including the parameters used, such as the body weight of animals, and their associated values), and the corresponding emissions of $\mathrm{NH}_{3}$ that are calculated and allocated to livestock activities (Merciai and Schmidt 2018; Castellani et al. 2017). The different ways co-products are handled in each modelling approach may also appear influent in the case of cattle, for which a share is coproduced by the activity of raw milk production in EXIOBASE 3.

\subsection{Contributions by elementary flows}

\subsubsection{Identification and comparison of the most contributing elementary flows}

The contribution analysis by elementary flows (substances emitted to the environment and resources consumed) enables (i) to identify the most impacting elementary flows along the supply chain of goods and services exchanged through EU trade, and (ii) to further analyze the reasons for the differences in impacts (and subsequent product contribution analysis) between the two modelling approaches. Firstly, considering the environmental impacts of imports, both modelling approaches identify a similar set of most contributing substances with respect to climate change, acidification, eutrophication (freshwater, marine, and terrestrial), photochemical ozone formation, and particulate matter, yet with relatively largely differing shares in some cases (Fig. 6). Fossil $\mathrm{CO}_{2}$ emissions to air are the main contributing substance to climate change in both modelling approaches, yet with a lower contribution according to IO analysis (66\% of the total impacts) compared to process-based LCA (76\%), while $\mathrm{CH}_{4}$ is the second contributor in both approaches (29\% versus $14 \%$ ). The larger contribution of $\mathrm{CH}_{4}$ according to $\mathrm{IO}$ analysis, as any difference in the contribution of substances between the two modelling approaches, can be related with the contribution analysis by products. Both the relatively large emission intensities along the supply chain of fuels and mineral oils in the IO framework, and the accounting for meat products and hotels and restaurant services, drive the larger contribution of $\mathrm{CH}_{4}$ emissions in IO analysis compared to process-based LCA.
Moreover, in both approaches, sulfur oxides $\left(\mathrm{SO}_{\mathrm{x}}\right)$ emissions to air are observed to be the main contributor regarding acidification (53\% and 78\% according to respectively IO analysis and process-based LCA), and the second contributor regarding particulate matter (PM) (20\% and 35\%). Similarly, both approaches identify $\mathrm{PM}_{2.5}$ emissions to air as the main contributing substance to impacts on particulate matter (respectively $64 \%$ in IO analysis and $60 \%$ in process-based LCA), and nitrogen oxides $\left(\mathrm{NO}_{x}\right)$ emissions as a key flow regarding several impact categories. However, whereas process-based LCA identifies $\mathrm{NO}_{x}$ emissions to air as the main contributing substance in terms of terrestrial eutrophication, marine eutrophication, and photochemical ozone formation (respectively $90 \%, 73 \%$, and $58 \%$ of the total impacts), IO analysis identifies a lower contribution (respectively, $34 \%$, $45 \%$, and $38 \%$ of the total impacts). Regarding terrestrial eutrophication, this result is to be put in perspective with the relatively important contribution of $\mathrm{NH}_{3}$ emissions to air to the total impacts of imports according to IO analysis (66\% compared to $10 \%$ according to process-based LCA), as driven by processed meat and hotels and restaurant that represent $60 \%$ of total $\mathrm{NH}_{3}$ emissions. Finally, in both cases of modelling approaches, phosphorus $(\mathrm{P})$ emissions to the environment drive the impacts on freshwater eutrophication, yet being reported in a different form (P to soil and to water in IO analysis versus phosphate and $\mathrm{P}$ to freshwater in the process-based LCA approach).

Considering resources, large (regarding fossils resource use and water use) to very large (regarding land use and minerals and metals use) differences are observed from one modelling approach to the other (Fig. 7). Both process-based LCA and IO analysis identify crude oil as a key contributor to the total impact on fossils resource use, yet representing different shares (respectively $84 \%$ and $49 \%$ ), IO analysis also identifying an important contribution of natural gas $(29 \%)$. In the process-based LCA approach, imported fuels and mineral oils is modelled by use of petroleum oils and oils obtained from bituminous minerals, crude (excluding natural gas condensates) as a proxy, which ultimately results in the lower contribution of natural gas to the impact of imports on fossils resource use compared to IO analysis. Moreover, IO analysis identifies grassland/pasture/meadow and unspecified land occupations as the inventory flows most affecting land use (representing respectively $35 \%$ and $32 \%$ of the total impact on land use), whereas process-based LCA identifies non-irrigated arable land occupation as the major occupation flow $(52 \%)$. Such difference in particular lies in the accounting of processed meat and hotels and restaurant in IO analysis (66\% of the total occupation of grassland/pasture/meadow). Finally, the contribution of elementary flows importantly differs from one modelling approach to the other regarding minerals and metals resource use: 


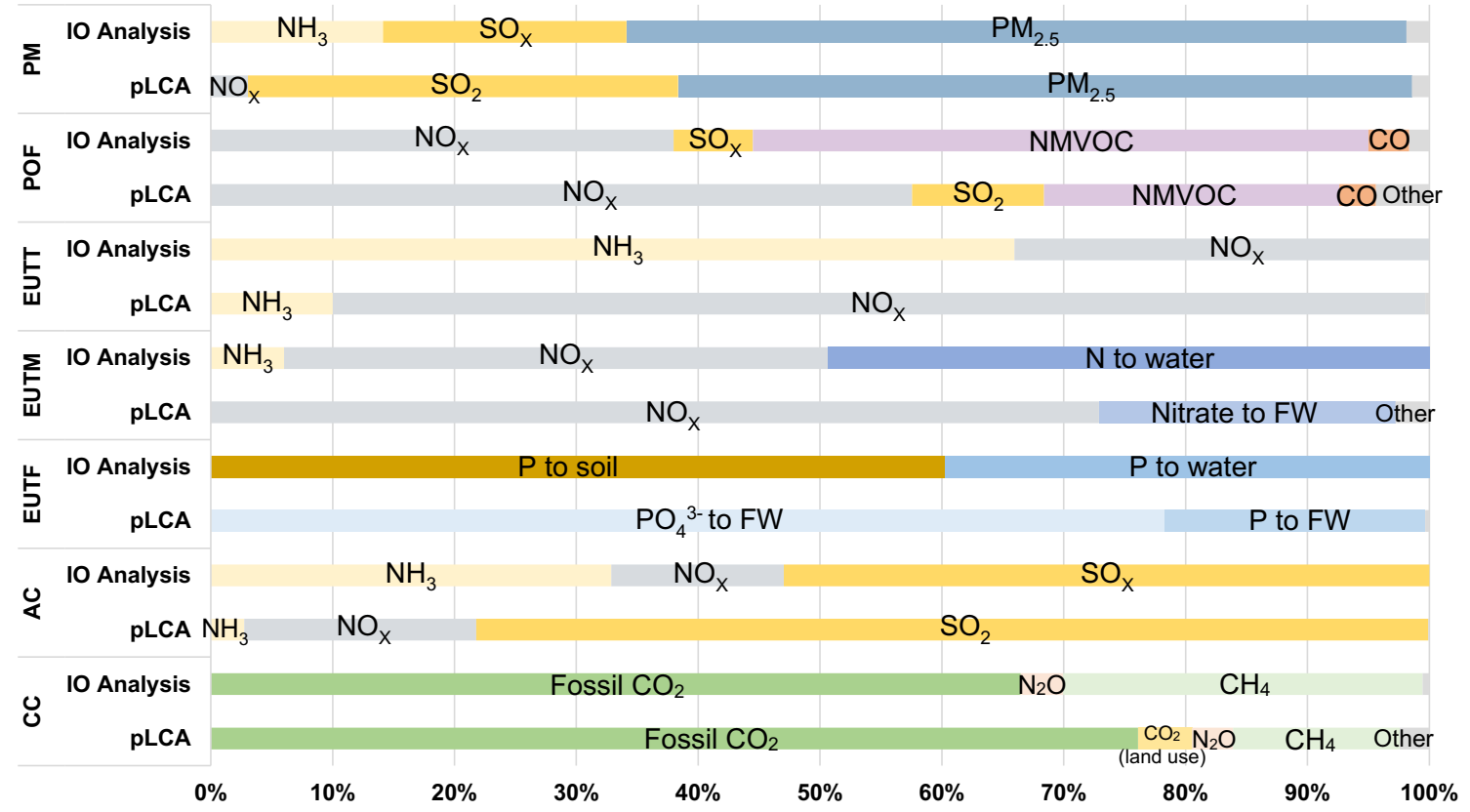

Fig. 6 Contributions of elementary flows to the environmental impacts of imports to the EU with respect to 7 environmental impact categories $(\mathrm{CC}$ : climate change, AC: acidification, EUTF: freshwater eutrophication,

gold and other industrial minerals are the main contributing resource flows according to IO analysis (respectively standing for $52 \%$ and $34 \%$ of the total impact), as opposed to copper and molybdenum in the process-based LCA approach (respectively $48 \%$ and 13\%), mainly due to machineries (Corrado et al. 2019). This difference in resource contributions is also a key driver to the differences in total impacts on minerals and metals resource use according to each modelling approach (Table 2). Firstly,
EUTM: marine eutrophication, EUTT: terrestrial eutrophication, POF: photochemical ozone formation, PM: particulate matter), considering

the relatively large contribution of other industrial minerals according to the results obtained from IO analysis, not observed in the process-based LCA approach (Table 3), is expected to entail in the meantime a large uncertainty in the total impact due to a high level of aggregation compared to other flows (as observed by Beylot et al. 2019 with respect to final consumption in the EU). Secondly, regarding several metals used in "small" quantities but whose characterization factors induce relatively

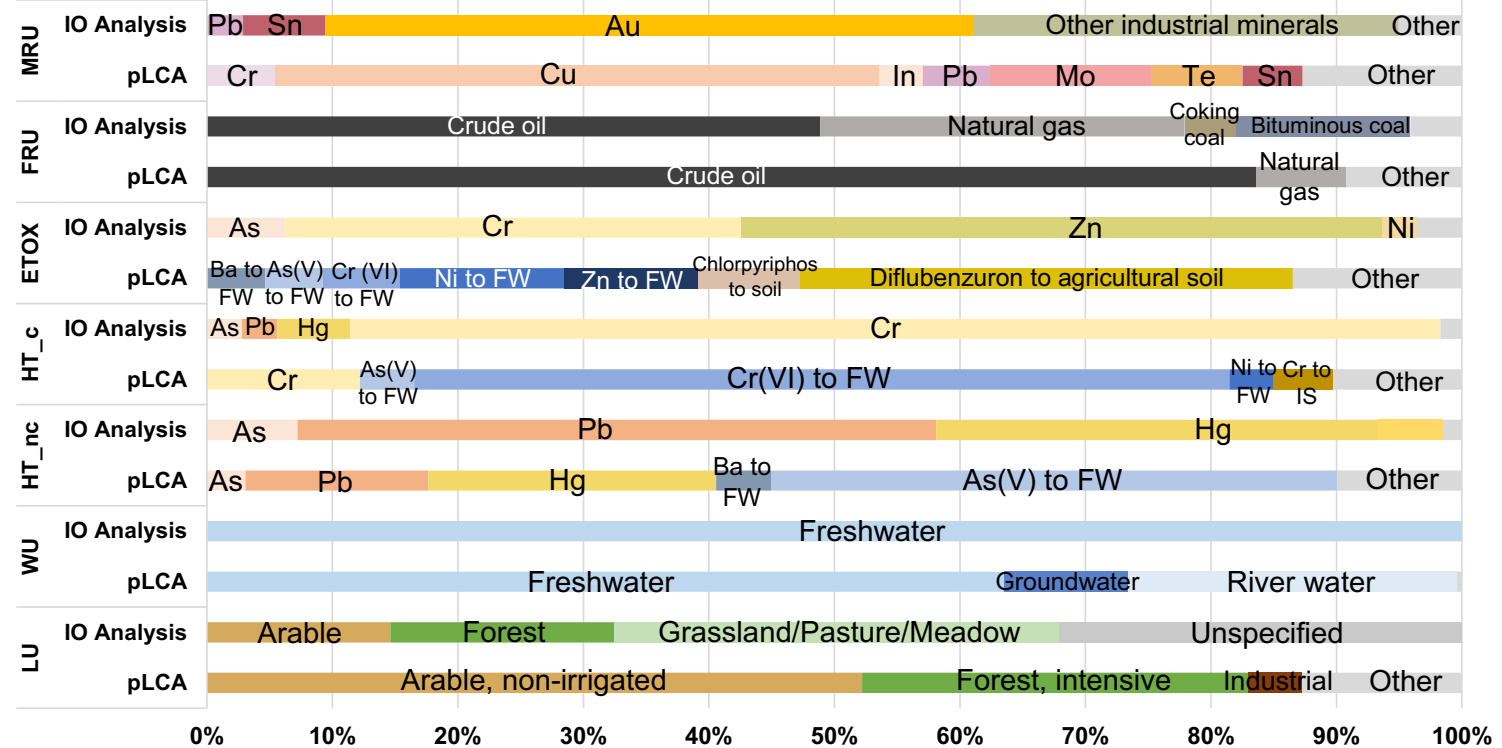

Fig. 7 Contributions of elementary flows to the environmental impacts of imports to the EU with respect to 7 environmental impact categories humn toxicity non-cancer, ETOX: freshwater ecotoxicity, FRU: fossil resource use, MRU: minerals and metals resource use), considering 
Table 3 Main resource flows contributing to the impact of EU imports on minerals and metals resource use: comparison of inventory and impact values according to IO analysis (year 2011) and process-based LCA (year 2010)

\begin{tabular}{|c|c|c|c|c|c|}
\hline \multirow[b]{2}{*}{ Unit } & \multicolumn{3}{|c|}{ (Uncharacterized) inventory flows } & \multicolumn{2}{|c|}{ (Characterized) impacts } \\
\hline & \multicolumn{3}{|l|}{ Mass (kg) } & Impact (kg Sb eq) & Process-based LCA \\
\hline Total mineral and metal resources & $2.30 \mathrm{E}+12$ & $8.65 \mathrm{E}+11$ & 3 & $2.79 \mathrm{E}+08$ & $3.78 \mathrm{E}+06$ \\
\hline Gold & $2.77 \mathrm{E}+06$ & $1.92 \mathrm{E}+03$ & 1447 & $1.44 \mathrm{E}+08$ & $9.97 \mathrm{E}+04$ \\
\hline Other industrial minerals & $1.11 \mathrm{E}+12$ & $3.19 \mathrm{E}+10$ & 35 & $9.44 \mathrm{E}+07$ & $1.65 \mathrm{E}+04$ \\
\hline Tin & $1.13 \mathrm{E}+09$ & $1.12 \mathrm{E}+07$ & 101 & $1.83 \mathrm{E}+07$ & $1.81 \mathrm{E}+05$ \\
\hline Lead & $1.26 \mathrm{E}+09$ & $3.21 \mathrm{E}+07$ & 39 & $8.02 \mathrm{E}+06$ & $2.03 \mathrm{E}+05$ \\
\hline Copper & $4.64 \mathrm{E}+09$ & $1.33 \mathrm{E}+09$ & 3 & $6.36 \mathrm{E}+06$ & $1.82 \mathrm{E}+06$ \\
\hline Molybdenum & na & $2.73 \mathrm{E}+07$ & na & na & $4.85 \mathrm{E}+05$ \\
\hline Chromium & na & 4.64E+08 & na & na & $2.05 \mathrm{E}+05$ \\
\hline Tellurium & na & $6.73 \mathrm{E}+03$ & na & na & $2.74 \mathrm{E}+05$ \\
\hline Indium & na & $1.91 \mathrm{E}+07$ & na & na & $1.32 \mathrm{E}+05$ \\
\hline Zinc & $6.30 \mathrm{E}+09$ & $2.07 \mathrm{E}+08$ & 30 & $3.39 \mathrm{E}+06$ & $1.12 \mathrm{E}+05$ \\
\hline Iron & $3.74 \mathrm{E}+11$ & $2.04 \mathrm{E}+11$ & 2 & $1.96 \mathrm{E}+04$ & $1.07 \mathrm{E}+04$ \\
\hline Aluminum & $1.69 \mathrm{E}+10$ & $1.64 \mathrm{E}+09$ & 10 & $1.84 \mathrm{E}+01$ & $1.80 \mathrm{E}+00$ \\
\hline Other mineral and metal resources & $7.89 \mathrm{E}+11$ & $6.26 \mathrm{E}+11$ & 10 & $4.36 \mathrm{E}+06$ & $2.57 \mathrm{E}+05$ \\
\hline
\end{tabular}

na not applicable

large impacts, IO analysis results in larger flows with differences amounting to several orders of magnitude compared to process-based LCA (factor 1447 of difference regarding gold, 101 regarding tin; Table 3). In the meantime, it is worth noting that regarding several base metals consumed in larger quantities (iron, copper, and to a lower extent aluminum), IO analysis also results in larger inventory flows compared to processbased LCA, but with a more limited difference (factor of difference ranging from 2 to 10). Such observations are in line with the larger difficulty to trace "small" metals compared to base metals when building both hybrid MRIO tables and LCIs. Finally, regarding human toxicity (cancer and noncancer) and freshwater ecotoxicity, the two modelling approaches importantly depart, primarily due to differences in the scope of environmental interventions considered. IO analysis identifies emissions of metals to air as representing almost the entire contribution to impacts on toxicity and ecotoxicity. On the contrary, process-based LCA identifies emissions of metals to air, but also to freshwater and soil, as well as emissions of pesticides to soil, as significant contributors.

Regarding the environmental impacts of exports, it can be noticed that the list of most contributing substances, their ranking and even their share is essentially similar to that of the case of imports (Electronic Supplementary Material, Document 1). Yet, some important differences can be observed, either specifically in one of the two modelling approaches or as confirmed by both approaches: larger contributions of forest land occupation regarding land use and of uranium regarding fossils resource use (in both modelling approaches), of $\mathrm{NO}_{x}$ emissions regarding photochemical ozone formation (according to IO analysis), and on the contrary lower contribution of diflubenzuron emissions to agricultural soil regarding freshwater ecotoxicity (according to process-based LCA).

\subsubsection{Influence of the larger scope of elementary flows in process-based LCA}

The larger number of elementary flows considered in processbased LCA especially influences the toxicity-related impact categories, for which it is a major driver for the differences observed between the two modelling approaches. The $15 \mathrm{sub}-$ stances that overall represent $100 \%$ of the impact of trade on human toxicity (cancer and non-cancer) and freshwater ecotoxicity in IO analysis (mostly emissions of metals to air) only contribute to 5 to $45 \%$ of the corresponding impacts in the process-based LCA approach (even between 5 and 14\% regarding freshwater ecotoxicity). The remaining share (55 to $95 \%$ of the impacts) is due to emissions not accounted for in IO analysis, in particular metals to water and pesticides to soil (representing 46 to $86 \%$ of the total toxicity-related impacts in the process-based LCA approach).

\subsection{IO analysis and process-based LCA: summarizing where the differences in impacts stem from}

Overall, this study highlights larger impacts calculated from IO analysis compared to process-based LCA. The accounting for services is one of the reasons for this divergence, yet explaining it to some extent only. In IO analysis, indeed, 
services stand for 7 to $16 \%$ of the total impacts of exports, and for 5 to $32 \%$ regarding imports. A similar comment applies to the difference in the mass of imports and exports in each approach (26\% and 5\% larger in IO analysis, respectively, regarding imports and exports).

On the contrary, this study identifies the differences in the impact intensities of goods, from one modelling approach to the other, as the main drivers for the differences in the total impacts and in the contribution analysis by products. These differences in impact intensities derive from the differences in life cycle inventories by product category as built according to each approach. Among the potential major sources for these differences, some are inherent to this study's modelling approach. The focus of the process-based LCA is the single product, which allows reaching a high level of detail in modelling the single supply chain, but at the same time poses some constraints on the broadness of the number of products which can be considered for the assessment. The assessment of the impacts of trade performed by Corrado et al. (2019) is based on the upscaling of process-based LCA results for 40 representative products. The choice for products as proxy representatives for each entire product category implies (i) excluding some products which appear relevant contributors to impacts according to IO analysis (e.g., meat products with respect to several impact categories) and (ii) assuming that the impacts associated with each entire product category are represented by those of a single representative product, potentially leading to biased estimations of the impacts (e.g., fuels and mineral oils represented by crude petroleum oils, in particular implying the underestimation of natural gas extraction).

Moreover, the impact intensities of goods may be significantly affected by some features inherent to the IO and LCI databases used to perform the calculations: (i) data sources for emissions to the environment, respectively, statistic-based (IO tables) or process-based (LCIs); (ii) data sources (including a balancing procedure; Merciai and Schmidt 2018) for the estimation of masses of products supplied and used within the economy, as a basis for the construction of EXIOBASE hybrid IO tables; (iii) the less complete coverage of elementary flows in the IO framework compared to process-based LCA (in particular, the exclusion of emissions of metals to water and of pesticides to soil in IO analysis, and the higher level of aggregation of mineral resource flows); and (iv) the way coproducts are handled in each modelling approach, respectively, by allocation in process-based LCA and by using the byproduct-technology model in IO analysis (which is equivalent to system expansion; Suh et al. 2010).

\section{Conclusions}

The assessment of the environmental impact of trade in the EU has been based on the comparison of two modelling approaches, namely IO analysis and process-based LCA. To support hotspot identification and subsequently decision making, a thorough interpretation of the results is needed. Both converging and diverging results have been identified and assessed. Regarding the diverging messages, the interpretation of the results has focused on the evaluation of a variety of aspects, encompassing, e.g., the methodological differences between the two approaches, the underpinning assumptions, the data coverage and sources, and the completeness of inventory as basis for impact assessment.

On the one hand, the two modelling approaches undertaken in this study, very different in nature, converge in:

- demonstrating that the EU was a net importer of environmental impacts in the period 2000-2010;

- showing an increase in impacts of EU imports and exports from 2000 to 2010 regarding most impact categories under study;

- showing that the EU trade balance (impacts of imports minus impacts of exports) has increased from 2000 to 2010 regarding most impact categories (respectively, 10 and 11 impact categories in the process-based LCA and IO analysis approaches);

- identifying manufactured products (in particular machineries and equipment, and vehicles) as the main contributors to the impacts of exports from the EU, regarding most impact categories;

- identifying products with more limited supply chains as the main contributors to the impacts of imports to the EU;

- identifying a similar set of most contributing substances regarding the impacts on climate change, acidification, eutrophication (freshwater, marine, and terrestrial), photochemical ozone formation, and particulate matter.

On the other hand, the two approaches importantly differ regarding several aspects:

- impacts of trade are calculated to be larger in the IO-based approach than in the process-based LCA approach, considering almost all the impact categories and years under study. In most cases, the discrepancy between results from IO analysis and process-based LCA is larger than a factor 2, and this factor is particularly large regarding terrestrial eutrophication, human toxicity (non-cancer), land use, and minerals and metals resource use;

- from 2000 to 2010, impacts from exports have increased at a larger pace than those from imports according to process-based LCA with respect to 13 impact categories out of the 14 under study, whereas IO analysis instead highlights a more balanced picture;

- the number of products included in the process-based LCA is relatively limited compared to the IO analysis. Therefore, process-based LCA identifies fuels and 
mineral oils as the main contributing good for most impact categories for imports, whereas IO analysis identifies different hotspots with fossil fuels as a key contributing category only regarding the impact on fossils resource use (and to a lower extent, on climate change). IO analysis instead identifies (i) food products (in particular products of meat), hotels and restaurant services, and to a lower extent agricultural products (that is, overall, products and services related to the food system) regarding acidification, terrestrial, freshwater, and marine eutrophication, land use, and water use, and (ii) materials, and of most importance metals (in particular basic iron and steel) and other materials and intermediate products (in particular rubber and plastic products) regarding human toxicity cancer and non-cancer, freshwater ecotoxicity, particulate matter, photochemical ozone formation, climate change, and minerals and metals resource use. It has to be highlighted that the products coverage of process-based LCA could be increased; however, this would be highly resource-demanding, and, in any case, it would be almost impossible to reach the broad coverage of IO analysis;

- in the process-based LCA, the life cycle inventory includes a higher number of substances than in the EEIOA, resulting in relatively large differences in the contribution analysis on substances regarding resource use (in particular land use and minerals and metals resource use), toxicity, and ecotoxicity indicators.

The inclusion of traded services in IO analysis only explains to a limited extent the difference in impacts from one modelling approach to the other. Instead, the impact intensity of goods, represented to be importantly larger in IO analysis as compared to process-based LCA (respectively considering years 2011 and 2010), is the main driver for the difference in the total impacts of trade. A consistency check of impact intensities between process-based LCI databases and IO databases, as e.g., initiated by Merciai and Schmidt (2018), appears key in the future to refine further the calculation of the environmental impacts of trade, and to potentially reduce the multiple divergences observed between the two modelling approaches. Despite such consistency check is out of the scope of this study, it is worth mentioning that limits in the environmental extensions of EXIOBASE 3 (namely absence of flows potentially key regarding toxicity and ecotoxicity aspects; and high level of aggregation regarding other industrial minerals) have been identified through this study. Moreover, the procedure implemented to select representative products and to upscale the results in the process-based LCA approach implies excluding product categories which appear key contributors in the environmental impact assessment according to IO analysis (in particular meat products). Both modelling approaches could, therefore, be further combined in a hybrid framework, enabling to benefit from the advantages of each other when performing the environmental assessment of EU trade. On the one hand, such framework would profit from the detailed inventories typical of processbased LCA. On the other hand, thanks to its ability to capture a broader picture of the impacts of economic activities, IO analysis could complement the selection of relevant representative products to be included in the analysis, as well as provide proxies for the impacts of services, captured in monetary units in trade statistics, and usually not modelled in process-based analyses.

Acknowledgments The authors would like to thank Michela Secchi and Alessandro Cerutti for their contribution to the calculation of the impacts of trade considering IO analysis, as well as Jannick Schmidt and Stefano Merciai for their support in the elaboration of results from EXIOBASE 3.

Funding The present study has been financially supported by the Directorate General for the Environment (DG ENV) of the European Commission in the context of the Administrative Arrangement "Indicators and assessment of the environmental impact of EU consumption" (No. 070201/2015/SI2.705230/SER/ENV.A1).

Open Access This article is distributed under the terms of the Creative Commons Attribution 4.0 International License (http:// creativecommons.org/licenses/by/4.0/), which permits unrestricted use, distribution, and reproduction in any medium, provided you give appropriate credit to the original author(s) and the source, provide a link to the Creative Commons license, and indicate if changes were made.

\section{References}

Beylot A, Secchi M, Cerutti A, Schmidt J, Sala S (2019) Assessing the environmental impacts of EU consumption at macro-scale. J Clean Prod 216:382-393

Castellani V, Fusi A, Sala S (2017) Consumer Footprint. Basket of Products indicator on Food, EUR 28764 EN, Publications Office of the European Union, Luxembourg, 2017, ISBN 978-92-7973194-5, doi:https://doi.org/10.2760/668763, JRC 107959

Corrado S, Rydberg T, Oliveira F, Cerutti A, Sala S (2019) Environmental impacts of trade in Europe: a bottom-up approach using life cycle assessment of representative products. Submitted to the Journal of Cleaner production

EC (2017) PEFCR Guidance document - Guidance for the development of Product Environmental Footprint Category Rules (PEFCRs), version 6.3, December 2017. Available at: http://ec.europa.eu/ environment/eussd/smgp/pdf/PEFCR_guidance_v6.3.pdf (Accessed July 2018)

EC (2018) DG trade. Statistical guide. European Commission. Directorate-general trade. June 2018

Eurostat (2018) Comext database - detailed statistics on international trade in goods. Available at: https://ec.europa.eu/eurostat. Accessed Oct 2018

Giljum S, Wieland H, Lutter S, Eisenmenger N, Schandl H, Owen A (2019) The impacts of data deviations between MRIO models on material footprints: a comparison of EXIOBASE, Eora, and ICIO. First published: 30 January 2019 https://doi.org/10.1111/jiec.12833,

Guan J, Zhang Z, Chu C (2016) Quantification of building embodied energy in China using an input-output-based hybrid LCA model. Energ Building 110:443-452 
Hamilton HA, Ivanova D, Stadler K, Merciai S, Schmidt J, van Zelm R, Moran D, Wood R (2018) Trade and the role of non-food commodities for global eutrophication. Nature Sustain 1(6):314-321

Heinonen J, Junnila S (2011) Case study on the carbon consumption of two metropolitan cities. Int J Life Cycle Assess 16(6):569-579

Hertwich EG, Peters GP (2010) Multiregional input-output database. OPEN:EU Technical Document. Technical document. Trondheim, 25 June 2010

Huppes G, De Koning A, Suh S, Heijungs R, Van Oers L, Nielsen P, Guinée JB (2006) Environmental impacts of consumption in the European Union: high-resolution input-output tables with detailed environmental extensions. J Ind Ecol 10(3):129-146

Kanemoto K, Moran D, Lenzen M, Geschke A (2014) International trade undermines national emission reduction targets: new evidence from air pollution. Glob Environ Chang 24:52-59

Lenzen M, Moran D, Kanemoto K, Foran B, Lobefaro L, Geschke A (2012) International trade drives biodiversity threats in developing nations. Nature 486:109-112

Leontief W (1970) Environmental repercussions and the economic structure: an input-output approach. Rev Econ Stat 52:262-271

Merciai S, Schmidt J (2018) Methodology for the construction of global multi-regional hybrid supply and use tables for the EXIOBASE v3 database. J Ind Ecol 22:516-531

Moran D, Wood R (2014) Convergence between the Eora, WIOD, EXIOBASE, and OpenEU's consumption-based carbon accounts. Econ Syst Res 26:245-261

Pairotti MB, Cerutti AK, Martini F, Vesce E, Padovan D, Beltramo R (2015) Energy consumption and GHG emission of the Mediterranean diet: a systemic assessment using a hybrid LCA-IO method. J Clean Prod 103:507-516

Peters GP, Minx JC, Weber CL, Edenhofer O (2011) Growth in emission transfers via international trade from 1990 to 2008. Proc Natl Acad Sci U S A 108(21):8903-8908

Rebitzer G, Loerincik Y, Jolliet O (2002) Input-output life cycle assessment: from theory to applications. 16th discussion forum on life cycle assessment. Int J Life Cycle Assess 7:174-176

Sala S, Beylot A, Corrado S, Crenna E, Sanyé-Mengual E, Secchi M (2019) Indicators and assessment of the environmental impact of EU consumption. Consumption and Consumer Footprint for assessing and monitoring EU policies with Life Cycle Assessment. Science for policy report. Publications Office of the European Union. https://doi.org/10.2760/403263
Schmidt J (2010) Documentation of the data consolidation and calibration exercise, and the scenario parameterization. Deliverable $n^{\circ} 6-1$ of the EU FP6-project FORWAST. Retrieved from http://forwast.brgm. fr/. Accessed Dec 2018

Stadler K, Wood R, Simas M, Bulavskaya T, de Koning A, Kuenen J, Acosta-Fernández J et al (2018) EXIOBASE3 - developing a time series of detailed environmentally extended multi-regional inputoutput tables. J Ind Ecol 22:502-515

Steen-Olsen K, Weinzettel J, Cranston G, Ercin AE, Hertwich EG (2012) Carbon, land, and water footprint accounts for the European Union: consumption, production, and displacements through international trade. Environ Sci Technol 46:10883-10891

Suh S, Weidema B, Schmidt JH, Heijungs R (2010) Generalized make and use framework for allocation in life cycle assessment. J Ind Ecol 14:335-353

United Nations (UN) (2012) Resolution adopted by the General Assembly on 27 July 2012. 66/288. The future we want

United Nations (UN) (2015) Sustainable development goals. Available at https://sustainabledevelopment.un.org/. Accessed July 2018

Weidema BP, Wesnæs MS (1996) Data quality management for life cycle inventories - an example of using data quality indicators. J Clean Prod 4(3):167-174

Weinzettel J, Hertwich EG, Peters GP, Steen-Olsen K, Galli A (2013) Affluence drives the global displacement of land use. Glob Environ Chang 23(2):433-438

Wiedmann TO, Schandl H, Lenzen M, Moran D, Suh S, West J, Kanemoto K (2015) The material footprint of nations. Proc Natl Acad Sci U S A 112(20):6271-6276

Wood R, Stadler K, Simas M, Bulavskaya T, Giljum S, Lutter S, Tukker A (2018) Growth in environmental footprints and environmental impacts embodied in trade: resource efficiency indicators from EXIOBASE3. J Ind Ecol 22(3):553-564

World Bank (2018) Households and NPISHs Final consumption expenditure (annual \% growth). Available at https://data.worldbank.org/ indicator/NE.CON.PRVT.KD.ZG. Accessed June 2019

Publisher's note Springer Nature remains neutral with regard to jurisdictional claims in published maps and institutional affiliations. 